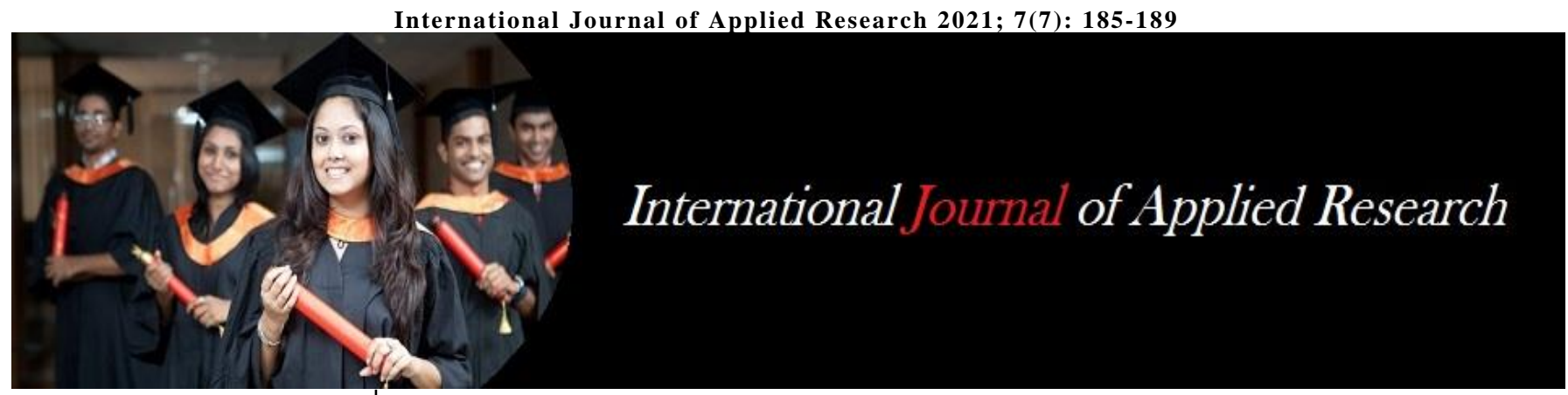

ISSN Print: 2394-7500 ISSN Online: 2394-5869 Impact Factor: 8.4 IJAR 2021; 7(7): 185-189 www.allresearchjournal.com Received: 24-04-2021 Accepted: 26-05-2021

Moumita Debnath Research Scholar, Tripura University, Tripura, India

Corresponding Author: Moumita Debnath Research Scholar, Tripura University, Tripura, India

\section{Phonological operations behind the prosodic restructuring in terms of reduction: A study of Tripura Bangla morphology}

\section{Moumita Debnath}

DOI: https://doi.org/10.22271/allresearch.2021.v7.i7c.8751

\section{Abstract}

The present paper offers a descriptive outline of prosodic restructuring of Tripura Bangla (TB) morphology in terms of reductionism. With the emergence of shrinkage form, varied strata of morphological input get affected. For in-depth study, the central debate instigates the invisible hidden properties of TB. These hidden properties are nothing but the underlying representation of prosodic behaviours. Stated differently, the study opens up several phonological operations control over the morphological input to give birth to an output i.e., TB. In contrast to TB, SCB does the job of morphological input here. The target of this ad ho scrutiny is to reveal the intention behind the transformation of morphological input. To reveal the real motif of 'relative' unmarkedness, several repair strategies have been uncovered in this discussion.

Keywords: Tripura Bangla (TB), Standard Colloquial Bangla (SCB), prosodic restructuring, morphological input, unmarkedness

\section{Introduction}

TB is the only medium of communication among a large number of tribes and non-tribes. The native speakers of TB conceive TB as both non-written and informal medium. From another point of view, they make an image of SCB as both written script and formal medium of communication. As per TB concerns, primary stress falls on the leftmost edge of the prosodic word resulting in disyllabic trochee. In case of tri-syllabic and hexa-syllabic word, one unparsed syllables get place at the right edge. In case of, four and seven syllable words, the two right most syllables outside the parsed syllables, remain unfooted. Strict iterativity does not get any place in TB grammar. Being insensitive language, there is no presence of heavy-light distinction. Instead of coda consonant, vowel gets moraic value to ensure the prosodic need of bimoraic trochee with the additional mora at the moraic level.

\section{Representative data}

Disyllabic words

k'o.wai (k $\mathrm{k}^{\mathrm{h}^{\prime}}$ o.wai) 'Khowai' bi.dal (b'i.dal) 'cunning'

Tetra-syllabic words

\begin{tabular}{|c|c|c|c|c|c|}
\hline Ji.pa.hi & (''i.фai) & 'constable' & bou.din.d्nI & (b'o.di) & 'sister-in-law' \\
\hline 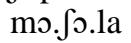 & (m'of.la) & 'spice’ & fa.li.ka & $\left(\int^{\prime} a \cdot l i \bar{i}\right)$ & 'sister-in-law' \\
\hline a.loif.jo & ('al.jî) & 'idleness' & tha.kur.b hai & $\left(\mathrm{t}^{\mathrm{h}^{\prime}} \mathrm{a} \cdot \beta \mathrm{ai}\right)$ & 'elder brother' \\
\hline ko.li.Ja & (k'oil.za) & 'lever’ & mo.hon pur & ( $\mu^{\prime}$ un.$\div$ ur $)$ & 'Mohanpur' \\
\hline a.ri.kel & (n'ai.hol) & 'coconut' & konbc.la & (k'om.ba.) & a 'which time' \\
\hline
\end{tabular}

Quadra-syllabic words

bo.ro da.da (b'od.da)

Ji.ra.ni.ya (z'i.rain.)na

db.ro.ni.ya ( $\quad$ ( $\mathrm{d}^{\mathrm{h}}$ o.roin.)na

tha.ku.ra.ni (t thak.rain)

com.pok.no.gor (s'om.фo)\#no.gor

rat.ri be.la (r'ait.ta.)la 'elder brother'

'Jirania'

'holder/catcher'

'priest's wife'

'Champak Nagar'

'at night' 
er $\mathrm{k}^{\mathrm{h}}$ an di.ya

ko.to.gu.li

('en.da)

ع.ț.gu.li

('kot.la)

('ct.la)

'through this side'

'how much'

'so much'

\section{Penta-syllables (Spanning two words)}

bou \# t ${ }^{\text {h}}$ a.ku.ra.ni (b'o.tain)

bra ${ }^{\mathrm{h}}$ m.mon \# ba.ri.ya (b'aun.bai).ra

'elder sister-in-law'

mot ${ }^{\mathrm{h}}$ \# cou.mu.ho.ni (m'os.so.)mu.ni

'Brahman Baria'

'Math

Choumuhoni'

[Jo.go.ho.ri.] [mu.ra] (z'o.goi).ra.(m`u.ra)'Jagahari Mura'

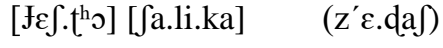

'wife's elder

sister'

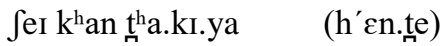

ke.mon ko.ri.ya $\quad\left(\mathrm{k}^{\prime} \varepsilon \mathrm{m} . \mathrm{b} \varepsilon\right)$

'from that place'

'through what

way'

\section{Mechanisms behind the prosodic reduction in Tripura Bangla (TB)}

The modus operandi of the prosodic reduction triggered by the need for ensuring the model of disyllabic word minimality condition in the name of shrinkage status of TB words impinging different levels - segment, syllable, foot, word and phrase. All the time the disyllabic requirement could not always be fulfilled, however. This will invite breach in communication. Through reduction, the number of syllables of the underlying form undergoes constriction in the output.

- Segmental Reduction or Weakening (Involving fricativization, devoicing, deaspiration, assimilation, vowel harmony, merger, deletion etc.)

- Syllable Reduction (Through diphthongization, deletion, metathesis-cum-deletion, medial syllable merger, coda deletion etc.)

- Foot deletion (Through syllable reduction, single word born of two-word compounds etc.)

- Word reduction (Through syllable deletion)

- Phrase reduction (Through syllable deletion (Adjective + Noun $\rightarrow$ Noun), foot deletion, and maximal reduction (Four syllable words $\rightarrow$ two syllable words)

All the above processes are demonstrated with the preceding data in the following table. The left most column specifies the nature of the reduction and the rightmost column contains the relevant remarks on the process.

Table 1: Mechanisms behind the prosodic reduction in Tripura Bangla (TB)

\begin{tabular}{|c|c|c|c|c|}
\hline Sl. No. & $\begin{array}{l}\text { Bangla in writing } \\
\text { and formal use in } \\
\text { Tripura }\end{array}$ & $\begin{array}{c}\text { TB only in } \\
\text { informal, spoken } \\
\text { form }\end{array}$ & Gloss & Remarks \\
\hline \multirow{2}{*}{ i. No deletion } & $\mathrm{k}^{\mathrm{h}}$ o.wai & $\left(\mathrm{k}^{\mathrm{h}^{\prime}}\right.$ o.wai $)$ & 'Khowai' & \multirow{2}{*}{$\begin{array}{l}\text { No deletion: as the base is by default a } \\
\text { disyllabic foot. }\end{array}$} \\
\hline & bi.dal & (b'i.dal) & 'cunning' & \\
\hline \multicolumn{5}{|l|}{ ii. Deletion at segment level } \\
\hline a. $\mathrm{C}$ deletion & Ji.pa.hi & ('’i.фai) & 'constable' & $\begin{array}{c}\text { CV.CV.CV } \rightarrow \text { CV.CV } \\
\left({ }^{\prime} \sigma \sigma\right) \sigma \rightarrow\left({ }^{\prime} \sigma \sigma\right) ; \text { segment deletion }=\text { syllable } \\
\text { merger }\end{array}$ \\
\hline b. V deletion & mo. Jo.la & (m'of.la) & ‘spice’ & $\begin{array}{c}\text { CV.CV.CV } \rightarrow \text { CV.CV } \\
\left({ }^{\prime} \sigma \sigma\right) \sigma \rightarrow\left({ }^{\prime} \sigma \sigma\right)\end{array}$ \\
\hline c. V, C deletion & a.loif.jo & ('al.ji) & 'idleness' & $\begin{array}{l}\text { CV.CVC.CV } \rightarrow \text { CV.CV } \\
\quad\left({ }^{\prime} \sigma \sigma\right) \sigma \rightarrow\left({ }^{\prime} \sigma \sigma\right)\end{array}$ \\
\hline d. Metathesis & ko.li.Ja & (k'oil.za) & 'lever' & $\begin{array}{c}\text { CV.CV.CV } \rightarrow \text { CVC.CV } \\
\left({ }^{\prime} \sigma \sigma\right) \sigma \rightarrow\left({ }^{\prime} \sigma \sigma\right)\end{array}$ \\
\hline e. Metathesis, $\mathrm{C}$ deletion & na.ri.kel & (n'ai.hol) & 'coconut' & CV.CV.CVC $\rightarrow$ CV.CVC $\left({ }^{\prime} \sigma \sigma\right) \sigma \rightarrow\left({ }^{\prime} \sigma \sigma\right)$ \\
\hline iii. Deletion at syllable level & & & & $\begin{array}{l}\text { At final positions: } \\
\left({ }^{\prime} \sigma\right)\left({ }^{\prime} \sigma \sigma\right) \rightarrow\left({ }^{\prime} \sigma \sigma\right)\end{array}$ \\
\hline $\begin{array}{l}\text { a. Weak final syllable in } \\
\text { trochee deleted }\end{array}$ & bou.di.di & (b'o.di) & 'sister-in-law' & $\begin{array}{l}\text { Weak syllable in trochee: } \\
\left({ }^{\prime} \sigma\right)\left({ }^{\prime} \sigma \sigma\right) \rightarrow\left({ }^{\prime} \sigma \sigma\right)\end{array}$ \\
\hline b. Final syllable deletion & Ja.li.ka & ( ('a.li) & 'sister-in-law' & $\begin{array}{l}\text { Unstressed, unfooted final syllable: } \\
\left({ }^{\prime} \sigma\right)\left({ }^{\prime} \sigma \sigma\right) \rightarrow\left({ }^{\prime} \sigma \sigma\right)\end{array}$ \\
\hline c. Medial syllable deletion & tha.kur.blai & (t $\left.\mathrm{t}^{\mathrm{\prime}} \mathrm{a} \cdot \beta \mathrm{ai}\right)$ & 'elder brother' & $\begin{array}{c}\text { Unstressed syllable in trochee deleted } \\
\left({ }^{\prime} \sigma \sigma\right)\left({ }^{\prime} \sigma\right) \rightarrow\left({ }^{\prime} \sigma \sigma\right)\end{array}$ \\
\hline $\begin{array}{l}\text { d. Weak syllable reduction } \\
\text { and deletion } \rightarrow \text { foot } \\
\text { reduction }\end{array}$ & $\begin{array}{l}\text { bo.ro \# } \\
\text { da.da }\end{array}$ & (b'od.da) & 'elder brother' & $\begin{array}{c}(\mathrm{CV} . \mathrm{CV}) \#(\mathrm{CV} . \mathrm{CV}) \rightarrow(\mathrm{CVC} . \mathrm{CV})\left({ }^{\prime} \sigma \sigma\right) \# \\
\left({ }^{\prime} \sigma \sigma\right) \rightarrow\left({ }^{\prime} \sigma \sigma\right) \\
\text { Two feet are squeezed to one. }\end{array}$ \\
\hline $\begin{array}{l}\text { e. Full/partial syllable } \\
\text { deletion }\end{array}$ & mo.hən\#pur & ( $\mu^{\prime}$ un. $\div$ ur) & 'Mohanpur' & $\begin{array}{l}\text { Weak syllable in first foot of compound. } \\
\qquad\left({ }^{\prime} \sigma \sigma\right)\left({ }^{\prime} \sigma\right) \rightarrow\left({ }^{\prime} \sigma \sigma\right)\end{array}$ \\
\hline $\begin{array}{l}\text { f i. Syllable deletion through } \\
\text { merger }\end{array}$ & fi.ra.ni.ya & (z'i.rain.)na & 'Jirania' & $\begin{aligned} & \text { CV.CV.CV.CV } \rightarrow \text { CV.CVC.CV }\left({ }^{\prime} \sigma \sigma\right) \sigma \sigma \rightarrow \\
&\left({ }^{\prime} \sigma \sigma\right) \sigma\end{aligned}$ \\
\hline f ii. Same: derived words & db.ro.ni.ya & ( $\mathrm{d}^{\mathrm{h}^{\prime}}$ o.roin.)na & holder/catcher' & $\begin{aligned} \text { CV.CV.CV.CV } \rightarrow & \text { CV.CVC.CV (' } \sigma \sigma) \sigma \sigma \rightarrow \\
& \left({ }^{\prime} \sigma \sigma\right) \sigma\end{aligned}$ \\
\hline \multirow{2}{*}{ g. multiple deletion } & tha.ku.ra.ni & (t thak.rain $)^{\prime}$ & 'priest's wife' & \multirow{2}{*}{$\begin{array}{c}\text { Reduction: segment, syllable deletion } \\
\sigma \sigma \sigma \sigma \rightarrow\left({ }^{\prime} \sigma \sigma\right) \\
\sigma \sigma \sigma \sigma \sigma \rightarrow\left({ }^{\prime} \sigma \sigma\right)\end{array}$} \\
\hline & bou.tha.ku.ra.ni & (b'o.tain) & 'elder sister-in-law' & \\
\hline $\begin{array}{l}\text { h. Syllable reduction through } \\
\text { coda deletion/relocation }\end{array}$ & com.pok \# nə.gər & (s'om.ф৩) \# nə.gor & $\begin{array}{l}\text { 'Champak } \\
\text { Nagar' }\end{array}$ & $\begin{array}{c}\text { CVC.CVC } \rightarrow \text { CVC.CV } \\
H H \rightarrow \text { HL/LL }(' \sigma \sigma) \rightarrow\left({ }^{\prime} \sigma \sigma\right) \\
\text { To ensure and ideal trochee. }\end{array}$ \\
\hline \multicolumn{5}{|l|}{ iv. Foot deletion } \\
\hline $\begin{array}{c}\text { a. Syllable reduction } \rightarrow \text { Foot } \\
\text { deletion }\end{array}$ & bra'm.mon \# ba.ri.ya & (b'aun.bai).ra & 'Brahman Baria' & $\begin{array}{c}\text { Two-word compounds } \rightarrow \text { single word } \\
\text { CVC.CVC } \rightarrow \text { CVC, CV.CV.CV } \rightarrow \text { CV.CV }\end{array}$ \\
\hline
\end{tabular}




\begin{tabular}{|c|c|c|c|c|}
\hline & & & & $\left({ }^{\prime} \sigma \sigma\right)\left({ }^{\prime} \sigma \sigma\right) \sigma \rightarrow\left({ }^{\prime} \sigma \sigma\right) \sigma$ \\
\hline $\begin{array}{c}\text { b. Syllable merger } \rightarrow \text { Foot } \\
\text { deletion }\end{array}$ & $\begin{array}{c}{\left[\mathrm{mot}^{\mathrm{h}}\right]} \\
\text { [cou.mu.ho.ni] }\end{array}$ & (m’os.so.)mu.ni & $\begin{array}{l}\text { 'Math Choumu- } \\
\text { honi' }\end{array}$ & $\left({ }^{\prime} \sigma\right)\left({ }^{\prime} \sigma \sigma\right) \sigma \sigma \rightarrow\left({ }^{\prime} \sigma \sigma\right) \sigma \sigma$ \\
\hline v. Word reduction & & & & Through syllable deletion \\
\hline a. & [Ғo.go.ho.ri.] [mu.ra] & (z'o.goi).ra.(m`u.ra) & 'Jagahari Mura' & $\left({ }^{\prime} \sigma \sigma\right) \sigma \sigma\left({ }^{\prime} \sigma \sigma\right) \rightarrow\left({ }^{\prime} \sigma \sigma\right) \sigma\left({ }^{\prime} \sigma \sigma\right)$ \\
\hline b. & $\begin{array}{c}\text { [go.no.raj] } \\
\text { [cou.mu.ho.ni] }\end{array}$ & \begin{tabular}{|c|}
$\begin{array}{c}\text { (g'on.ras.)so } \\
\text { (m`u.ni })\end{array}$ \\
\end{tabular} & $\begin{array}{l}\text { 'Ganaraj Choumu- } \\
\text { honi' }\end{array}$ & $\left({ }^{\prime} \sigma \sigma\right) \sigma\left({ }^{\prime} \sigma \sigma\right) \sigma \sigma \rightarrow\left({ }^{\prime} \sigma \sigma\right) \sigma(' \sigma \sigma)$ \\
\hline vi. Phrase reduction & & & & $\begin{array}{c}\text { Via syllable deletion: } \\
\mathrm{A}+\mathrm{N} \rightarrow \mathrm{N} \text { via foot reduction: }\end{array}$ \\
\hline a. Syllables deletion & {$\left[\mathrm{J} \varepsilon \int \cdot \mathrm{t}^{\mathrm{h}} \mathrm{\rho}\right]\left[\int \mathrm{a}\right.$.li.ka] } & $\left(z^{\prime} \varepsilon . d a f\right)$ & 'wife's elder sister' & $\left({ }^{\prime} \sigma \sigma\right) \#\left({ }^{\prime} \sigma \sigma\right) \sigma \rightarrow\left({ }^{\prime} \sigma\right)\left({ }^{\prime} \sigma \sigma\right) \rightarrow\left({ }^{\prime} \sigma \sigma\right)$ \\
\hline \multirow{2}{*}{ b. Foot deletion } & [kon] [be.la] & (k'om.ba.)la & 'which time' & $\left({ }^{\prime} \sigma\right) \#\left({ }^{\prime} \sigma \sigma\right) \rightarrow\left({ }^{\prime} \sigma\right)\left({ }^{\prime} \sigma \sigma\right) \rightarrow\left({ }^{\prime} \sigma \sigma\right) \sigma$ \\
\hline & [rat.ri] [be.la] & (r'ait.ta.)la & 'at night' & $\left({ }^{\prime} \sigma \sigma\right)\left({ }^{\prime} \sigma \sigma\right) \rightarrow\left({ }^{\prime} \sigma \sigma\right) \sigma$ \\
\hline \multirow{3}{*}{ c. Maximal reduction } & eI k $k^{\text {han di.ya }}$ & ('cn.da) & 'through this side' & $\sigma \sigma \sigma \sigma \rightarrow\left({ }^{\prime} \sigma \sigma\right)\left({ }^{\prime} \sigma \sigma\right) \rightarrow\left({ }^{\prime} \sigma \sigma\right)$ \\
\hline & ke.mon ko.ri.ya & $\left(\mathrm{k}^{\prime} \varepsilon \mathrm{m} \cdot \mathrm{b} \varepsilon\right)$ & 'through what way' & $\sigma \sigma \sigma \sigma \sigma \rightarrow\left({ }^{\prime} \sigma \sigma\right)\left({ }^{\prime} \sigma \sigma\right) \sigma \rightarrow\left({ }^{\prime} \sigma \sigma\right)$ \\
\hline & kə.to.gu.li & ('kot.la) & 'how much' & $\sigma \sigma \sigma \sigma \rightarrow\left({ }^{\prime} \sigma \sigma\right)\left({ }^{\prime} \sigma \sigma\right) \rightarrow\left({ }^{\prime} \sigma \sigma\right)$ \\
\hline
\end{tabular}

\section{Major phonological processes behind the emergence of TB}

The followings are the several phonological processes that play the key role behind the projection of the variety of Bangla called Tripura Bangla (henceforth TB).

\subsection{Metathesis}

Trask (1996:222) defines metathesis as "Narrowly, an exchange in the positions of two segments in a word, either as a historical change or as a synchronic rule......." Through metathesis, the location of the two segments in a word undergoes transposition. A sample of data related to this are cited in (1).

1.

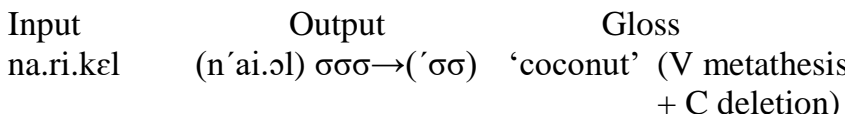

Ji.pa.hi (J'i.фai) $\sigma \sigma \sigma \rightarrow\left({ }^{\prime} \sigma \sigma\right) \quad$ 'constable'(V metathesis + C deletion)

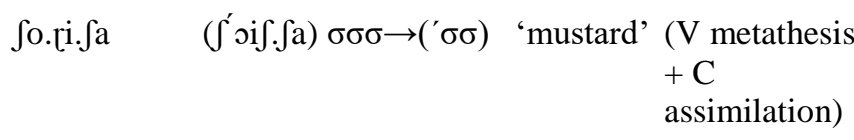

mo.ri.ca (m'oic.ca) $\sigma \sigma \sigma \rightarrow\left({ }^{\prime} \sigma \sigma\right)$ 'rust' (V metathesis $+\mathrm{C}$ assimilation)

\subsection{Merger}

Merger is a sort of phonological process through which syllable merger takes place through metathetical relocation of monophthongs into diphthongs. Consequently, longer sequences turn into smaller ones i.e. moving towards unmarked. For illustration, some TB words are presented in (2) below.

2. Input Output Ji.ra.ni.ja (z'i.rain).na $\sigma \sigma \sigma \sigma \rightarrow\left({ }^{\prime} \sigma \sigma\right) \sigma \quad$ 'place name' $\mathrm{d}^{\mathrm{h}}$ O.ro.ni.ja (d'o.roin).na $\sigma \sigma \sigma \sigma \rightarrow\left({ }^{\prime} \sigma \sigma\right) \sigma^{\prime}$ holder/catcher'

\subsection{Segmental weakening}

For the sake of speech simplification, some feature drop out in replace of another neighbouring feature in the name of segmental weakening which is supposed to be a licit form of universal vocabulary. TB also follows the same route. The mapping between SCB or SB and TB show how the transformation occurs by the weakening processes (i.e. aspiration to deaspiration, voicing to devoicing and plosive to fricativization). This weakening happens both in dominant and non-dominant position. For illustration, look at (3).

3.

\begin{tabular}{|c|c|c|}
\hline Input & Output & Gloss \\
\hline pap & $\left(\phi^{\prime} \mathrm{a} \phi\right)$ & 'sin’ \\
\hline $\mathrm{d}_{\pi}^{\mathrm{h}}$ an & (d'an) & 'paddy' \\
\hline re.ga & (r'c.ha) & 'REGA' \\
\hline pũ.ti & ( $\phi^{\prime}$ u.di) & 'kind of fish' \\
\hline
\end{tabular}

\subsection{Vowel harmony}

Vowel harmony is a kind of structural idiosyncrasy, the influence of which the quality of vowels of the underlying forms gets affect through sharing certain features with contrastive vowels in a phonological words or phrases. The followings are the ideal instance of vowel harmony in TB. In (4i) o transforms to $u$ to harmonize with the vowel of the following syllable by complete assimilation. In (4ii), o becomes $\mathrm{u}$ by adopting the feature [+High] from the high vowel $\mathrm{i}$ in the first syllable.

4.

Input Output Gloss

i. mo.hon \# pur (m'un.фur) $\sigma \sigma \sigma \rightarrow($ ' $\sigma \sigma)$ 'Mohanpur'

ii. [bri.hof.po.thi.][bar] (b'i.fut).bar $\sigma \sigma \sigma \sigma \sigma \rightarrow($ ' $\sigma \sigma)$ 'Thursday'

\subsection{Assimilation}

Assimilation is a feature alternation of phonological segments in a word or phrase. For phonetic convenience, one segment turns into more similar to other nearby segment. It is a common phonological process regardless of diachronic and synchronic study in linguistics. The journey from the morphological input (compatible to SCB) to output (i.e., TB) shows the same phonological process. In support of the above statement, some considerable examples from TB have been projected below.

5.

\begin{tabular}{|c|c|c|}
\hline Input & Output & Gloss \\
\hline i. [mot] [cou.mu.ho.ni] & (m’os.so.) mu.ni & 'Math \\
\hline 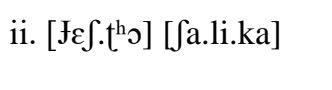 & (z'c.daf) & $\begin{array}{l}\text { 'wife's } \\
\text { elder sister' }\end{array}$ \\
\hline
\end{tabular}


In (5) the input segments t and c alter into s in (5i); and (5ii) represents the alternation of the input segment th into $d$ (i.e., output.

\subsection{Deletion: Segment, syllable, foot, coda}

Deletion (elision) is a type of phonological process on condition of structural well formedness triggering the omission of one or more segment from a word or phrase. This depletion affects every prosodic tier (such as segment, syllable, foot, prosodic word and prosodic phrase etc.). The key role behind this is to project the well-formed structure of the word in the form of shrinkage condition. For relevant data, consider the examples (6-12) below.

\subsubsection{Coda deletion}

Coda deletion means deletion of the marginal consonant of the right side in a syllable. Cross-linguistically, this is much unmarked practice and TB is also in touch with it. For example-6.

\section{Input \\ i. com.pok \# no.gor \\ ii. non.d. \\ iii. ra.nir \# ba.zar \\ Output \\ (s'om.фo) \# no.gor \\ (n'on.dor) \# no.gor \\ (r'a.ni) \# ba.zar \\ Gloss \\ 'Champaknagar' \\ 'Nandannagar' \\ 'Ranirbazar'}

The above data shows that $\mathrm{CV}$ is preferred over CVC in the foot internal structure. As per present context of TB, coda consonant of non-head position of the disyllabic trochee undergoes deletion or depletion. In words (i), (ii), (iii) of the section (6) underlying CVC in the weak second syllable of the disyllabic trochees goes to $\mathrm{CV}$ under the prosodic onus of an ideal trochee of ('CVC.CV) or ('CV.CV).

\subsubsection{Syllable deletion}

In the name of phonological process, morphemic input gets affect under pressure from prosody in deletion at the syllable level. Syllable deletion takes place in respect of gaining shrinkage form through several syllable positional deletion in a word: weak final syllable deletion, medial syllable deletion, partial syllable deletion and full syllable deletion and so on. The following of $\mathrm{TB}$ are the considerable evidence of the above statements.

\section{7.}

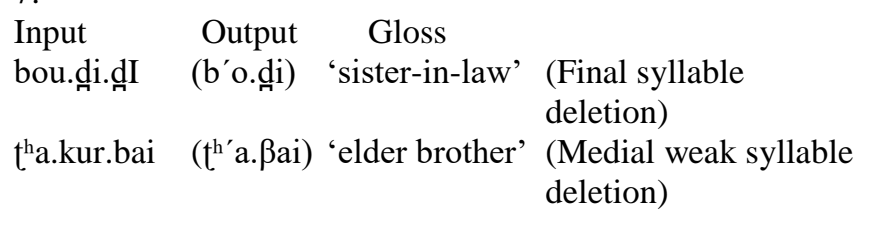

mo.hon \# pur (m'un.фur) 'Mohanpur' (Part of the syllable deleted)

\subsubsection{Segment deletion}

Segment deletion means the loss of consonant or vowel or both consonant and vowel as per contextual requirement. From the following data (8), it is to be noted that segment deletion arise alongside metathesis to reduce the large sequences in a word.

8. Input a.loif.jo Output ('al.ji) na.ri.kel

mo. So.la ('mos.la)

'spice'

\subsubsection{Foot deletion}

Through foot deletion, one or more syllable undergoes deletion to attain the minimum word requirement. Hence, the following data projects how the outputs have been gained via inputs in terms of reductionism.

9.

Input Output Gloss

i. $\left(\mathrm{m}^{\prime} \mathrm{t}^{\mathrm{h}}\right)\left(\mathrm{c}^{\prime}\right.$ ou.mu. $)$ ho.ni (m'os.so).mu.ni

'Mathchoumuhoni'

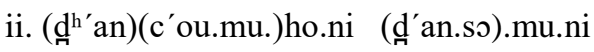

'Dhanchoumuhoni'

In (i) \& (ii) of (9) shows two coterminous trochaic foot of the underlying forms get shortened into one at the overt form. Alongside, the unfooted first syllable (ho) in the second phase undergoes deletion. Assimilation crops up in case of the coda of the initial monosyllabic foot in (i) and onset of the second foot in (i) \& (ii).

\subsection{Word reduction}

Word reduction refers to the reduction of word of longer sequence into a smaller one. Through word reduction, one or more syllable lose their existence in a particular word domain. Relevant TB data are cited in (10) below.

10.

$\begin{array}{ll}\text { Input Output } & \begin{array}{l}\text { Gloss } \\ \text { (. [Jo.go.ho.ri.] [mu.ra] }\end{array} \\ \begin{array}{l}\text { 'Jagaharimura' } \\ \begin{array}{l}\text { ii. [go.no.raf] [cou.mu.ho.ni] } \\ \text { 'Ganaraj choumuhoni' }\end{array}\end{array} & \text { (g'on.ras.)so.(m`u.ni) }\end{array}$

Data (i) of 10 shows multiple phonological processes under word reduction such as assimilation $(\mathrm{J} \rightarrow \mathrm{z})$ and diphthongization via metathesis $(\mathrm{o} \rightarrow \mathrm{oi})$. Data (ii) manifests merger or metathesis via vowel deletion (go.no $\rightarrow$ gon), assimilation $(\mathrm{f} \rightarrow \mathrm{s}, \mathrm{ou} \rightarrow \mathrm{o})$, and syllable deletion (ho).

\subsection{Phrase reduction}

Phrase reduction refers to the state of being reduction of two adjacent feet signifying two phrases at the syntactic level. It occurs through foot/syllable merger and syllable deletion. The following data reveals $[\mathrm{AP}]+[\mathrm{NP}] \rightarrow[\mathrm{NP}]$ via reduction in the internal make-up of the phrases i.e. feet.

11.

Input

Phrases

i. [kon] [be.la] (k'on) (b'c.la) (k'om.ba.)la 'which time'

ii. [rat.ri] [be.la] (r'at.ri) (b'c.la) (r'ait.ta.)la 'at night'

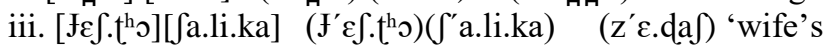
elder sister'

\subsection{Maximal reduction}

Through maximal reduction, underlying phrases have been reduced into minimum prosodic word of one syllabic trochee in the output. In due course, it affects segments, syllables and feet by triggering merger or deletion. The following TB data (12) are the considerable evidence of the above statement. 
12.

\begin{tabular}{|c|c|c|}
\hline \multicolumn{3}{|c|}{ Output } \\
\hline Phrases & Foot & \\
\hline [ko.to][gu.li] & (k'o.to)(g'u.li) & 'how much' \\
\hline [ع.to] $[$ gu.li] & ('c.to)(g'u.li) ('ct.la) & 'so much’ \\
\hline $\begin{array}{l}{[\mathrm{eI}]\left[\mathrm{k}^{\mathrm{h}} \mathrm{an}\right][\text { di.ya }]} \\
\text { side' }\end{array}$ & ('ei)(k $k^{\mathrm{h}^{\prime}}$ an)(d'i.ya) ('cn.da) & 'through this \\
\hline $\begin{array}{l}{[\mathrm{k} \varepsilon . \mathrm{mon}][\mathrm{ko.rI} . j \mathrm{a}]} \\
\text { which way' }\end{array}$ & (k'c.mon)(k'o.rı.ja) & 'through \\
\hline
\end{tabular}

\section{Objectives of the study}

- The research will seek to find out the secret behind the systematic reduction of the SB/SCB words and morphemes.

- The immediate hypothesis is that a mass reduction wave is at work underlying to fulfil the demands of a disyllabic trochee as the ideal minimal word in the output in TB. Hence, TB adopts various alterations causing multiple phonological changes to the morphological input to satisfy the disyllabic word minimum.

- This reductionism dictated by prosody opens up a vista of research possibilities in the area of 'Movement towards the Prosodically Unmarked'. In this respect, the present research aims to pinpoint the core properties of UG that are operative in TB.

\section{Finding}

The major findings have been recapitulated in the following-

- $\quad \mathrm{TB}$ is the spoken and informal variety of Bangla used in Tripura as a lingua franca.

- Compared to the formal variety found in the written and standard communication, TB displays a massive transformation through restructuring of the formal inputs.

- This restructuring is a reduction at the prosodic level dictated by the 'latent' prosodic grammar of TB.

- This reduction process is extremely systematic and rulegoverned.

- These latent and deep-rooted factors work behind the screen in accomplishing the attested reduction processes operating on input morphemic sequences at the levels of segment, syllable, foot, word and phrase.

- These contraction processes are at par with Universal Grammar and are cross-linguistic. These are not idiosyncratic features of TB.

- The findings of the work will help the TB speakers to be more careful and motivated while attempting to learn any Second Language including English.

\section{References}

1. Das Shyamal. Some Aspects of the Prosodic Phonology of Tripura Bangla and Tripura Bangla English. Doctoral dissertation. Central Institute of English and Foreign Languages, Hyderabad ROA 4932001.

2. Essays in Linguistics: Studies in Phonology, Syntax and Sociolinguistics, Akanksha Publishing House. New Delhi 2009.

3. 'Aspiration: A Dying Phenomenon in Bangla'. MS 2010.

4. Essays in Linguistics II: Studies in Syntax, Phonology and Morphology. Akanksha Publishing House. New Delhi 2011.

5. “All for a Trochee”. MS 2012.
6. "The Emerging Alphabet of Tripura Bangla: A Metrical Account', The EDRC Journal of Learning and Teaching. edited by Professor Dr. M. Maniruzzaman et al., eds. Dhaka, Bangladesh 2016;1(2):12-23. www.edrcbd.org.

7. "Language Change-Why and How: A Case Study of Tripura Bangla via-a-vis its Use in Media", Dhwani Vandanan, symposium proceeding, The English and Foreign Languages University 2017.

8. "Language Change, Media and Standardization", Aligarh Journal of Linguistics, Ali R. Faithi et al. (eds.) Aligarh 2018;7(2);1-28.

9. Trask RL. A Dictionary of Phonetics and Phonology. Routledge. New York 1996. 